\title{
UMA PROPOSTA DE ENSINO INTEGRADO
}

Vera Brenner Eilert

Departamento de Geociências. Centro de Ciências Naturais e Exatas. UFSM. Santa Maria, RS.

Irma Peroni

Departamento de Matemātica. Centro de Ciēncias Naturais e Exatas. UFSM. Santa Maria, RS.

Maria Nascimento Barnewitz

Departamento de Metodologia de Ensino. Centro de Educação. UFSM. Santa Maria, RS.

Naida Lena Pimentel

Departamento de Química. Centro de Ciências Naturais e Exatas. UFSM. Santa Maria, RS.

Anamaria Lopes Rodrigues

Departamento de Estudos Políticos e Sociais. Centro de Ciências Sociais e Humanas. UFSM. Santa Maria, RS.

RESUMO

0 presente estudo consiste numa anālise interpretativa de conceitos e abordagens sobre Ensino Integrado tendo como suporte teó rico a concepção piagetiana de desenvolvimento mental e a concepção gestaltista de aprendizagem.

0 objetivo é propor uma sistematização renovadora do ens $\underline{i}$ no, coerentes com as diretrizes vigentes, a qual, desenvolvendo o raciocínio lógico e uma consciência crītica, capacite o estudante a solucionar problemas e a discernir entre opções em valores condizen tes com a natureza humana.

SUMMARY

EILERT, V.B.; PERONI, I.; BARNEWITZ, M.N.; PIMENTEL, N.L. and RODRI GUES, A.L., 1983. A proposal on integrated teaching. Ciêneia e Natura, 5:59-74.

The present papers consists of an interpretative analysis of concepts and approaches on Integrated Teaching. Its theorethical suport comes from the Piagetian concept of mental development and the gestalt concept of learning.

Its purpose is to propose a renewed systematization coherent with current teaching directions, which through the development of logical reasoning and a critical mind help make the student capable in solving problems and deciding between options in values according to human nature.

\section{INTRODUÇÃO}

0 saber, hoje, apresenta-se fragmentado. Os especialistas em geral, se restringem às suas āreas de conhecimento; as Univers $\underline{j}$ 
dades são organizadas em compartimentos por sua vez divididos e subdivididos; são valorizadas pesquisas em campos cada vez mais res tritos e diversificados, acelerando-se, assim, a desintegração do saber (14, p.219).

As possíveis soluções dos grandes problemas extrapolam, na maioria dos casos, o domínio de uma única ciência e os pesquisado res que, via de regra, sabem muito sobre muito pouco, não conseguem resolver a maioria das questões sem auxîlio de outros especialistas.

0 homem, pressionado simultâneamente por comportamentos sociais conservadores e inovadores, por teorias econōmicas não raro contrastantes, por ideologias muitas vezes conflitantes, sentindo-se cada vez mais confuso e isolado, tende a buscar uma interpretação unitária do mundo que o cerca.

No campo da educação - processo cultural que inclui o de senvolvimento de todas as potencialidades humanas - o fenōmeno da fragmentação do saber constitui obstáculo à formação integral do họ mem.

A Escola tradicional seleciona conteüdos, divide-os em dis ciplinas cujo domínio pelo aluno tem sido, desde hā muito tempo, ava liado de forma empírica. A validade dos conteūdos escolhidos e a prätica da avaliação vēm sendo questionadas na atualidade. Entre os principais fatores responsāveis por este questionamento destaca-se, de um lado, o desenvolvimento científico e tecnolōgico deste ūltimo sēculo que provocou uma busca de especializações e sofisticações na prōpria especialização, gerando, inclusive, linguagens diversificadas; de ou tro lado, o acesso à escola, em nümero crescente, de uma clientela até então excluîda, oriunda de classes sociais menos favorecidas.

A Escola tem sido focalizada sob os aspectos diferentes tanto por psicólogos como por sociōlogos. Os psicólogos da Escola Piagetiana preocupam-se, principalmente, em saber como a inteligên cia das crianças evolui geneticamente; os Gestaltistas enfatizam a percepção no fenômeno da aprendizagem; outros, ainda, como Rogers, investigam o desenvolvimento da personalidade e suas implicações no campo do ensino.

A sociologia, apesar de ser uma ciência relativamente no va, tem contribuĩdo com experiēncias no sentido de verificar como o meio social pode influir na educação. Nesta āréa, são vārios os es tudos a destacar:

- influēncia que a família, o meio e a classe social exer cem sobre o educando;

- o papel da educação no sentido da coesão social e do ajus tamento do educando à sociedade em que vive;

- adequação do ensino à clientela à qual se destina;

- adaptação da linguagem ao meio social onde está inserida a escola. 
Evidencia-se, atualmente, uma tendēncia, no sentido de se estabelecer uma concepção interdisciplinar do ensino, fundamentada na constatação de que o Universo tem uma unidade imanente.

No Brasil, apesar da Lei $5692 / 71$, são reduzidas em número as pesquisas sobre interdisciplinaridade tomada como sinonimo de in tegração (4, p.98). Esta metodologia que representa uma tentativa de sanar a visão fragmentada que normalmente se tem do processo edu cativo, requer uma reformulação profunda no que tange à harmoniza ção da filosofia da educação e das teorias psicológicas e sociais adotadas com a prātica em sala de aula. Isso exige uma mudança na formação do professor, em seu posicionamento frente à educação, na visão que a sociedade deve ter da educação e na polîtica administra tiva frente à distribuição de encargos docentes nas escolas.

Não resta dūvida de que a escola vai sofrer transformações bem maiores que modificações de currículos, mudanças estas sem valor se o corpo docente não se inteirar do problema, não for conveniente mente motivado, orientado e treinado para resolvē-lo em consenso. E tambēm, claro que a escola não pode sofrer mudanças bruscas porque não se tem notīcia de que alguma delas tenha sido proveitosa.

Segundo MOORE (6, p.67) em Educação é impossîvel para um autor criar uma teoria geral comprovada cientificamente em todas as variāveis e sob todos os pontos de vista, mas permanece a necessida de de uma fundamentação teórica para todo o professor que queira rea lizar um trabalho eficiente e coerente.

No ensino, se não é possīvel verificar diretamente de for ma cientîfica todo o mecanismo de aprendizagem, é aceitávẹl construir metodologias com base em conclusões procedentes de fontes consagra das, qualquer que seja a sua origem. Na seleção destas fontes ē re levante, mas não essencial, verificar se tais estudos foram compro vados cientificamente, porque mesmo entre contribuições não compro vadas desta forma, hā algumas de ponderāvel interesse educacional. E, tambēm, vālido adotar algumas inovações, desde que se apresentem coerentes e a partir de propostas bem fundamentadas (6, p.68).

Face ao exposto, as autoras do presente estudo propõem-se a apresentar uma anālise interpretativa de conceitos e abordagens de ensino integrado, selecionados à luz de teorias de aprendizagem, com a finalidade de sugerir uma alternativa de ensino adaptāvel à realidade atual, visando substituir um ensino predominante informa tivo por outro que, a partir do raciocīnio lōgico, capacite o estu dante à solução de problemas e lhe proporcione condições de desenvol ver uma consciēncia crítica.

PRESSUPOSTOS TEORICOS BASSICOS

origem do pensamento integrador 
No século XII, com a criação das primeiras universidades, os eruditos e seus discípulos trabalhavam juntos, dentro de uma con cepção unitāria do conhecimento (concepção aristotélico-tomista).

A partir de Galileu foi introduzida na Ciência a quantifi cação dos fenōmenos, o que seu início ao processo da fragmentação do saber, que, com o desenvolvimento da Ciência e da Tecnologia, se diversificou em ramos cada vez mais especializados. Este fato refle tiu-se no ensino superior, descaracterizando-o e desvirtuando o pa pel da Universidade como agente de transmissão de cultura.

Segundo GUSDORF, citado por ZILLES (14, p.229) "... a Ci ência em migalhas de nossa época não passa de reflexo de uma cons ciência em migalhas, incapaz de formar uma imagem de conjunto do muñ do atual. Donde os desequilíbrios ontológicos de que padece nossa civilização...".

A atual crise de identidade que se manifesta através de violência e do uso de töxicos, antes de ser encarada como um fato excepcional, não seria produto desta quebra de harmonia na formação integral da personalidade?

Atualmente, observa-se nos meios intelectuais uma tendên cia para retomar a visão unificada das ciências, o que tem origina do controvērsias. Em Educação, enquanto, por um lado, deseja-se pre servar no 30 grau elevados padrões de ensino nas disciplinas tradi cionais e perseguir o conhecimento por si mesmo, de outro lado, pre coniza-se que as Universidades adaptem currículos e programas às exi gências atuais como meio de integração dos indivĩduos na sociedade.

Na década de 1950, houve tentativas de embasar o ensino de 20 grau em novos princípios de conhecimento. São dessa época ino vações como o Movimento da Matemática Moderna, os Materiais Produzi dos pela Comissão de Estudo das Ciências Físicas (PSSC), Sistemas de Projetos Químicos (CBA e CHEMS) e o Estudo Curricular de Ciências Biológicas (BSCS). No Brasil, a partir da ūltima reforma de ensino, as escolas estão, aos poucos, reagindo contra a abordagem acedêmica e o carāter especializado dos cursos de 20 grau. Como solução racio nal, no ensino básico tem sido proposto em lei o ensino integrado (2). E essencial, entretanto, precisar o que se entende por ensino integrado e como se pretende realizā-1o.

Formas de integracão

Integração pressupõe uma combinação de partes interrelacio nadas a fim de constituir o todo.

o termo integração tem vārias acepções, por vēzes contras tantes, conforme as filosofias educacionais, os objetivos visados e as abordagens de acesso ao tema.

Quanto à natureza da integração, PIAGET (5, p.2-6) estabe leceu níveis em termos de pesquisa e atuação entre professores uni versitārios. 
0 primeiro nível - inferior - denominado "multidiscipli nar" é alcançado quando a solução de um problema em uma disciplina requer informações de outros setores do conhecimento, que atuam co mo ciência auxiliar e que não se enriquecem pela integração ocorri da. Piaget exemplifica:

"... na Geologia, um especialista em tectōnica necessita de dados paleontológicos e mineralógicos para reconstruir a histōria e expli car a formação de uma cadeia de montanhas. Estas informações são in dispensáveis para a tectōnica; no entanto, não hā ação no sentido in verso, ou seja, a tectōnica, como tal, não explicară a evolução das espécies paleontologicas nem a estrutura dos minerais...".

"... reservamos o termo "interdisciplinar" para caracteri zar um segundo nivel de integração, no qual a colaboração entre dis ciplinas diversas ou setores heterogêneos de uma mesma ciência coñ duza a uma certa reciprocidade nos intercâmbios, de maneira que exis ta um enriquecimento mūtuo. Trata-se, então, de analisar e classī ficar diversos tipos de interação, o que não é fácil. Porēm, se nos̄ sa hipōtese de partida estā justificada, isto $\bar{e}$, se a fragmentação das ciências depende das fronteiras do que é observado, e se a in terdisciplinaridade resulta de uma busca de estruturas mais profuñ das que os fenomenos, estruturas estas destinadas a explicā-los, po de-se supor que os tipos de integrações interdisciplinarizadas sáo adequadas às diversas relações entre estruturas...".

0 mesmo autor admite um terceiro nível, superior, de inte gração, que denomina "transdisciplinar", o qual consistiria em cone xões no interior de um sistema total. Piaget justifica esta hipóte se com o fracasso das tentativas de reduzir o inferior ao superior e vice-versa, enquanto que as tentativas de assimilação recíproca têm tido êxitos. Exemplificando, a coordenação final entre as teo rias mecânica e ondulatōria resultou na teoria mecânico-ondulatōria. Outra justificativa apresentada por Piaget é que delimitações pura mente fenomenîsticas impedem que as ciências sejam gerais e exempli fica dizendo que a Física só será geral depois de ter englobado a Biologia e a Psicologia. De fato, para estudar os movimentos de um homem, é necessārio conhecê-1o sob os pontos de vista biológico e psicológico, além de conhecer as leis da mecânica.

FREDERICK (7, p.35-45) relata que no Congresso de Varna (1968) para o Ensino Integrado das Ciências, foi estabelecido, em con senso, que um currículo pode ser considerado integrado, sob o ponto de vista cientỉfico, quando possui uma estrutura unificada e, para organizā-la, foram caracterizadas quatro formas típicas de aborda gem.

1. Abordagem de esquemas conceituais

Nesta abordagem, a unidade estrutural não fica limitada a um enfoque de Química, Física, Biologia ou outros, mas advém de pla nejamento a partir de conceitos amplos como, por exemplo, "poluição do ar", "ecologia", "conservação de energia".

2. Abordagem de pesquisa

Neste caso, a unidade estrutural advēm da organização de 
atividades de forma que o aluno, a partir da solução de problemas sim ples, vai adquirindo habilidades para resolver outros problemas ca da vez mais complexos e aprendendo a aplicar estas habilidades em si tuações semelhantes.

3. Abordagem de relevância

Atravēs desta abordagem, o estudo é estruturado em torno de problemas de relevāncia social e de utilidade cientîfica. Este tipo de abordagem que admite uma relação intelecto-afetiva de cará ter integrativo, implica em fazer com que o indivíduo, depois de ter assimilado um determinado fato ou conteúdo, seja capaz de uma refle xão a respeito do que foi aprendido, reflexão esta feita através do pensamento crítico, no sentido de sua auto-realização social.

4. Abordagem de processo

Consiste em adotar o método cientîfico como elemento inte grador no planejamento de āreas de estudo. 0 foco de interesse recai mais sobre o processo metodolōgico mental de abordagem das ciēncias do que sobre o processo mnemómico, isto ē, quando o estudo das dis ciplinas se desenvolve atravēs das etapas do mētodo cientîfico, o processo de reflexão, integrador de conteūdos, predomina sobre a aquisição de informações.

Aplicando o conceito piagetiano de interdisciplinaridade à metodologia do ensino, para se chegar à integração, poder-se-ia considerā-la uma abordagem por processo mental. 0 modelo de ensino a que se.pretende chegar - e que visa o estabelecimento de uma estru tura mental estāvel - pode partir de uma taxionomia de objetivos ade quada ao treinamento de desempenhos mentais do educando, treinamen to este que conduza ao domínio de um conjunto de competências em grau de crescente complexidade. Não é necessārio nem possível para o edu cando adquirir todo o conhecimento cientifico contemporâneo ou sa ber fazer sofisticadas pesquisas científicas.

0 que importa é que ele "saiba" encontrar, oportunamente, - que the convëm entre as informações "armazenadas" em livros, re vistas, museus, computadores elou outras fontes de informações, fa zer críticas consistentes, levantar alternativas e obter resposta que permitam resolver problemas de forma satisfatōria.

ENSINO INTEGRADO BASEADO NA ABORDAGEM POR PROCESSOS - BASES PSICOLOGICAS A gênese e a evolução da inteligência, segundo Piaget

Tratando-se de estruturas em termos gerais, são estas ou de natureza concreta ou de natureza abstrata, ambas com caracteres de universalidade e necessidade. Jean Piaget infere de suas experiên cias que as estruturas mentais, ao mesmo tempo em que têm uma gêne se, isto é, que se constroem no tempo, podem alcançar as caracterís 
ticas intemporais da necessidade e da universalidade das estruturas Iógico-matemāticas, passando por estruturações sucessivas ( 3, p.77; 13, p.342).

Piaget vale-se de imagens da Fĩsica para afirmar que a es trutura mental seria um estado de equilibrio entre os componentes do psiquismo. Quando desenvolvida, a inteligência atinge o estado de equilíbrio estāvel, isto é, volta a equilibrar-se se afastada do mes mo por ação de influências novas, organizando-se em estruturas pro gressivamente mais sofisticadas (9, p.11; 93 e 105).

Diz Piaget:

"A equilibração progressiva, ao nível das sequências pro babilisticas, constitui, de fato, um processo essencialmente tempo ral, pois este comporta uma ordem de sucessão de construções onde căa da uma depende da precedente. Mas o equilíbrio al cançado comporta umá estrutura intemporal pois um equilíbrio consiste em uma compensação geral de todas as transformações virtuais do sistema (...)"(3, p.77).

Para caracterizar os estāgios do desenvolvimento cogniti vo Piaget $(7$, p.35-50; 11, p.40-44; 10, p.46; 12, p.45-50), conside ra fundamentais dois critērios: o da reversibizidade, isto é, a ca pacidade do individuo de executar a mesma ação nos dois sentidos do percurso, tendo consciência de que está fazendo ou desfazendo a mes ma coisa; e o da conservação da matéria, isto é, o entendimento dos aspectos físicos variāveis da matēria (substância, peso, volume e outros), aquisição esta que se estrutura em etapas sucessivas do desenvolvimento. A noção de conservação de volume evidencia o início do pensamento operatório.

Em relação aos estāgios do desenvolvimento cognitivo (F gura 1) no período chamado sensōrio-motor no estágio que vai do naśs cimento até dois anos aproximadamente, notam-se as ações reflexas sem

\section{DESENVOLVIMENTO COGNITIVO}

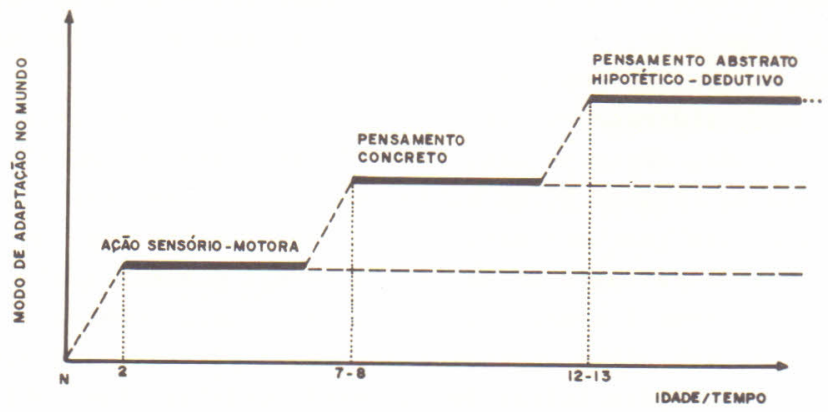

FIGURA I. Desenvolvimento cognitivo segundo Pioget, in DENIS - PRINZHORN, Marienne - Cours du Professeur "Psycopedagogie I". Recueil de Tex tes. Génève, 1979. 
nenhuma reversibilidade. o processo de organização dos sistemas de esquemas mentais, nesta fase inicial é caracterizado por pequenas modificações que se efetuam no sistema, nas proximidades de sua po sição de equilîbrio; modificações maiores não têm registro. A seguir, até aos sete anos, temos o chamado "período do pensamento intuitivo" no qual as ações sensörio-motoras começam por implicar em represen tações a partir de manipulação de elementos concretos, chegando à combinação de pensamentos e, às vezes, atē à coordenação dos mesmos. 0 indivỉduo não tem a consciência da reversibilidade das ações em ge ral, mesmo que em alguns casos saiba efetuar tais reversões; entre tanto, pode jā efetuar modificações maiores a partir da posição es tāvel, sem desequilibrar-se. Estas modificações são semi-reversíveis. Dos sete aos doze anos, "período das operações concretas", 0 indi vỉduo vai aumentando a consciência das ações. Estas suas ações inte riorizadas reversiveis, coordenadas em estruturas locais. A modifi cação, a partir da posição estāvel, pode ser gradualmente aumentada sem perda do equilibrio. Aos doze anos inicia-se o "período das ope rações formais", prōprias do pensamento adulto. A lógica concreta ine rente à coordenação das ações do adulto è resultante de estruturas mentais biológicas, que são estruturas orgânicas específicas para o ato de estabelecer relações lögicas. A partir dessas concepções, Pia get, inspirando-se nos "grupos" da matemätica, criou um modelo no qual denominou de "agrupamentos" os processos mentais cujas leis de funcionamento baseiam-se nas operações diretas, nas operações inver sas e na identidade.

$\mathrm{Na}$ Figura 2 tentou-se representar graficamente a concepção piagetiana dos nīveis de reversibilidade adquiridos por indivíduos tidos como normais nas diversas faixas etārias e do fenōmeno de re equilibração, que aumenta com a idade e é representado pelo āngulo de abertura $\left(r^{1}, r^{2}, r^{3}\right)$ no movimento pendular; o grau de reversibi lidade $\left(g r_{1}, g r_{2}, g r_{3}\right)$ é representado pelo comprimento do percurso do pēndulo no sentido horārio.

Reconsiderando os objetivos propostos no presente traba 1ho, cabe, ainda, destacar que, para Piaget, conforme M00RE(6, p.70), o pensamento da criança è, em muitos aspectos, diferente do pensa mento adulto, sem ser, por esta razão, nem inferior nem ineficiente. As estruturas conceituais de um adulto normal o torna häbil a si tuar-se num sistema ordenado de estruturas espaço-temporais - a es tabelecer relações entre objetos e idéias, a abstrair sua atenção de objetos concretos para outros de natureza abstrata, bem como a pen sar em termos de causa e efeito. 0 adulto tende a pensar que a sua mente e a da criança trabalham de forma semelhante o que, não acon tece. Métodos de ensino apropriados para adultos são inadequados pa 
ra crianças. Deve ser preocupação do mestre usar linguagem e propor trabalhos adequados ao tipo de pensamento do qual a criança é capaz. Propor a uma criança, em nível de operações concretas, conteúdos e métodos que requeiram pensamento formal, alēm de desperdïcio de tem po, poderá ser fonte de frustrações.

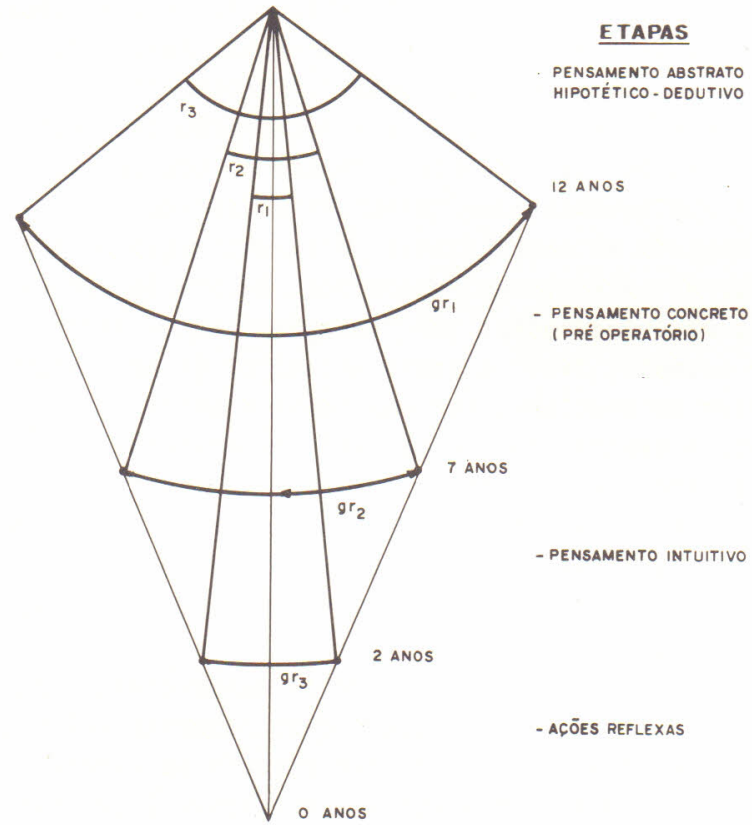

FIGURA 2. Representaçāo da concepcāo piagetiana dos niveis de reversibilidade.

Ao estudar estratégias para melhorar o processo ensino-a prendizagem, $\bar{e}$ imprescindivel ter presente que a criança é um ser em desenvolvimento não somente sob o ponto de vista cognitivo; $\bar{e}$ um to do complexo, dotado de outros caracteres, tais como, por exemplo, afetivos e psicomotores tambëm em desenvolvimento, que influenciam de forma expressiva sua aprendizagem.

Mecanismo da aprendizagem segundo a teoria da forma ou gestaltismo A teoria psicológica da percepção total, conhecida como Teoria da Forma* teve entre seus precursores Guillaume e MerleauPonty, e se desenvolveu na Alemanha com Koffka (1926), Koehler (1929) e Wertheimer (1945).

\footnotetext{
* A expressão "Teoria. da Forma" jā havia sido utilizada anteriormen te por Kurt Goldstein para denominar uma teoria por ele concebida, fundamentada na constatação de que cada organismo possui uma estru tura global, não sendo possĩvel afetar um órgão sem perturbar o todo.
} 
Segundo esta teoria, a aprendizagem se realiza pela per cepção em três "momentos". No primeiro, denominado "sîncrese", no qual se dá o contato do intelecto com o conhecimento novo, a apren dizagem limita-se a uma concepção global, difusa, na qual se desta ca a idéia central. A seguir, esse conhecimento inicial difuso vai se distribuindo pelas estruturas prē-existentes, o que conduz à rarac terização de aspectos essenciais inter-relacionados do tema em fo co, constituindo-se o processo dito "anālise". Finalmente, a apren dizagem só se efetiva se houver a reintegração das partes no todo, numa reorganização "sui generis", de acordo com as estruturas ante riores, e è configurada numa "sintese" subjetiva.

Segundo os Gestaltistas, a aprendizagem se dā por "insights", ou seja, por discernimentos repentinos. De acordo com esta concepção, aprender é, essencialmente, ter "insights" em um todo insignificati vo; é, por exemplo, "ver" o ponto essencial de um argumento, "captar" como resolver um problema, ter uma idéia significativa, vislumbrar de improviso o sentido do que se está investigando. A cada novo "insight" a estrutura cognitiva anterior se modifica e se torna pro gressivamente mais receptiva a novos "insights".

Como inferência desta teoria, o método pedagōgico mais efi ciente é o que dá condições para tais "insights", levado à captação do significado de situações globais.

E importante salientar que os Gestaltistas puros contes tam a teoria de ensino-aprendizagem dita associacionismo, segundo a qual é fundamental a resposta do indivíduo a um determinado estîmu 10 exterior; a conexão entre ambos é reforçada e automatizada pelo treinamento de mecanismos psīquicos naturais, controlados sob enfo que meramente objetivo, sem considerar as experiências conscientes, a exatidão da informação verbal e a significação para o indivĩduo.

os Associacionistas, por sua vez, contestam os Gestaltis tas por não se preocuparem com as causas do fenômeno da percepção.

Assumindo um ponto de vista menos radical, pode-se cons $\underline{i}$ derar que no processo ensino-aprendizagem Hā diferentes tipos de at vidade e diversos tipos de compreensão, admitindo-se que em alguns tipos de atividades e nos niveis mais baixos de compreensão (em que não hā necessidade de se alcançarem resultados mais significativos para o indivīduo) podem ser ūteis as técnicas associacionistas.

o Gestaltismo sob ponto de vista de Piaget

Piaget nos mostra que seus "esquemas" constituem sistemas de conjuntos anālogos às "gestalten" (formas", com exceção dos es quemas característicos do 50 estāgio (experiências para ver) e os atos de inteligência relativos que estão fora dos domīnios da Ges talt pura (8, p.248-287). 
Para Piaget, a teoria da forma reduziria a inteligēncia à percepção e esta seria prē-formada a partir do interior (apriorismo inverso), e, por isto, acabaria se parecendo com a percepção empir $\underline{i}$ ca (apriorismo direto) que é prē-formada a partir do exterior.

"Nossa crítica à teoria da forma consiste, então, em reter tudo o que de positivo ela opõe ao associacionismo... rejeitando tu do o que a torna um empirismo inverso. Concluindo, criticar o ges taltismo não é rejeitá-lo e sim tornā-lo mais maleāvel e, em conse quência, substituir seu apriorismo por um relativismo genético". (8, p. 287 ).

A aceitação, por parte de Piaget, da interpretação gestal tista sobre estruturas cognitivas, ainda que dentro de um relativis mo genético, justifica a proposta de orientar a aprendizagem levan do o aluno a raciocinar segundo o mētodo cientifico, com base na ex plicação piagetiana sobre amadurecimento intelectivo e na organiza \&ão de conhecimentos segundo a Gestalt.

PROPOSTA DE ENSINO INTEGRADO POR PROCESSO

Principios orientadores do planejamento num ensino integrado por pro cesso - Bases metodológicas

0 ponto de partida para o planejamento do ensino integra do por "processo", isto é, por organização e reorganização das estrü turas mentais estāveis que correspondem a capacidade cada vez mais complexas de raciocīnio, é a verificação do estāgio de desenvolvi mento da inteligência (idade psicolögica). Tal verificação pode ser efetivada atravēs de testes de desempenho em nîveis cujo rendimento é controlável pela observação sistemática e pela mensuração conven cional segundo taxionomias em domīnio cognitivo. Assim, um aluno que tenha feito um curso com "currículo por atividades" organizado segun do a legislação vigente no Brasil (2), deverā, ao finalizā-lo, evị denciar aptidão para iniciar um estudo de âmbito globalizado mais abrangente e complexo, ou seja, deverá apresentar condições de in gresso num currículo por área de estudo. Nessa estratēgia de contro le, o minimo de condições exigidas seria que esse aluno demonstras se, em qualquer ārea de estudo, capacidade de:

- captar e expressar a idéia central de um tema numa ati vidade planejada;

- extrair e expressar conceitos básicos;

- destacar com clareza e precisão aspectos essenciais con tidos no tema;

- sintetizar, com exatidão, assuntos estudados.

$\mathrm{Na}$ perspectiva do presente estudo, a organização sistemá tica, pelo docente, de condições externas para oportunizar a apren dizagem, constitui os chamados "procedimentos". Estes, para serem 
integradores segundo a abordagem adotada, deverão, necessariamente, corresponder às etapas do método científico (Figura 3). Com isto, oportunizar-se-ā ao estudante seja qual for a matēria em estudo, um tipo de aprendizagem coerente com a natureza do mecanismo de aquis $\underline{i}$ ção de conhecimentos e a habilitação para uma atitude científicạ.

\begin{tabular}{|c|c|c|}
\hline METODO CIENTIFICO & $\begin{array}{c}\text { MOMENTOS DA APRENDIZAGEM } \\
\text { PELA PERCEPÇÃO }\end{array}$ & $\begin{array}{c}\text { APRENDIZAGEM POR PROCESSO } \\
\text { INTEGRADOR }\end{array}$ \\
\hline $\begin{array}{l}\text { A) Proposição e de } \\
\text { limitação do proble } \\
\text { ma. }\end{array}$ & 1. Sincrese & $\begin{array}{l}\text { 1. Expressar a idēia } \\
\text { centra1. }\end{array}$ \\
\hline $\begin{array}{l}\text { B) Formulação de } \\
\text { hipöteses. }\end{array}$ & & $\begin{array}{l}\text { 2.1. Destacar elementos } \\
\text { essenciais. }\end{array}$ \\
\hline $\begin{array}{l}\text { C) Coleta e regis } \\
\text { tro de dados. }\end{array}$ & 2. Anālise & $\begin{array}{l}\text { 2.2. Caracterizar e } \\
\text { classificar as } \\
\text { pectos importan } \\
\text { tes. }\end{array}$ \\
\hline $\begin{array}{l}\text { D) Anālise e in } \\
\text { terpretação dos } \\
\text { dados. }\end{array}$ & & $\begin{array}{l}\text { 2.3. Exemplificar com } \\
\text { fatos especificos. }\end{array}$ \\
\hline E) Conclusão. & . & $\begin{array}{l}\text { 3.1. Sintetizar, com } \\
\text { exatidão de in } \\
\text { formação, assun } \\
\text { tos estudados. }\end{array}$ \\
\hline F) Generalização. & & $\begin{array}{l}\text { 3.2. Aplicar em fatos } \\
\text { especificos. }\end{array}$ \\
\hline
\end{tabular}

Figura 3. Quadro sinótico da aplicação de princīpios integradores.

o objetivo principal da aprendizagem è a construção e o desenvolvimento dos sistemas operatōrios da inteligência. Entretan to, não há possibilidade de alcançā-lo sem passar pela aprendizagem de conteüdos de disciplinas como "meio" de ensino.

$\mathrm{Na}$ operacionalização do ensino-aprendizagem deve-se, por tanto, atentar para os seguintes aspectos:

- A proposição de um problema implica na existência de um determinado conteúdo que, por sua vez, faz parte de uma matéria.

- Os problemas propostos devem ser bem claros para o alu no, caso contrário ele não terá condições psicolōgicas de solucio nā-los. 
- Na proposição de problemas, deve-se levar em conta o es tāgio de desenvolvimento do sistema operatório do aluno.

$\mathrm{Na}$ efetivação da aprendizagem evidenciam-se dois aspectos:

- a reelaboração do sistema operatōrio do educando;

- a aquisição de novos conceitos e de novos pontos de re ferēncia.

Estes dois aspectos são interdependentes porque ē a par tir de conteūdos assimilados, considerados pontos de referência, que o sistema operatório se amplia e, ampliando-se, adquire novos pon tos de referência. Neste enfoque, a aquisição de pontos de referēn cia obedece a uma sequencia de descontinuidades. Cabe ao professor, ao estabelecer estratēgia de ensino, levar em consideração o proces samento dessas descontinuidades, o que vem auxiliar o aluno a avan çar na referida sequência.

Segundo BORDENAVE (1, p.221) "... o desenvolvimento de uma atitude científica depende das experiencias vividas pelos estudan tes, e isto, por sua vez, depende da metodologia de ensino-aprendí zagem empregada pelos professores".

As tēcnicas de interpretação e montagem de textos e reso lução de problemas poderão constituir-se num dos procedimentos inte gradores na aquisição da atitude cientĩfica.

Da condução do processo depende a aquisição de competên cia para a extrapolação. Da extrapolação, o indivĩduo pode chagar à criatividade que, neste caso, vem a ser uma forma de transcender os parāmetros conceituais assimilados.

Avaliagão

Partindo da idēia de que todo ensino deve ser desenvolvi do de forma tão científica quanto possivel, pode-se afirmar que a avaliação do produto deste ensino vem a ser o aspecto da ciēncia aplicada que comprova a validade científica do processo. Assim sen do, qualquer instrumento de controle da eficiência (do processo) e da eficácia (do produto) deve apresentar, com o máximo rigor poss $\underline{i}$ vel, características de validade (adequação) e de fidedignidade (pre cisão).

Considerando o conteūdo organizado de uma disciplina ou de uma unidade de programa como meio de treinamento de desempenhos mentais, para controlar o grau de desenvolvimento dessas habilidades è necessārio:

- que o individuo evidencie que domina um conjunto de co nhecimentos;

- que para evidenciar esse domỉnio, o individuo tenha con. seguido uma forma de expressão coerente, ordenada e precisa;

- que para obtenção dessas evidências se disponha de um instrumento de controle que realmente venha a captar a eficiēncia 
do processo atravēs da eficācia expressa em domínio de conteúdos.

No ensino proposto - ensino integrado, abordagem por pro cesso - a avaliação abrangẹ duas dimensões, ou seja, avaliação de eficācia (do produto) e avaliação da eficiência (do processo).

Avaliąão da eficácia e da eficiência

$\mathrm{Na}$ avaliação do produto faz-se necessāria a adoção de pa râmetros para que qualquer prova cumulativa ou não, escrita, oral ou prática, seja organizada de modo a proporcionar ao aluno condições de:

- evidenciar dominio de conhecimentos;

- evidenciar capacidade de análise atravēs da seleção de aspectos caracteristicos de um tema proposto;

- aplicar conhecimentos teóricos;

- expressar resumidamente e com precisão a idéia central e seus aspectos caracteristicos, evidenciando capacidade de sinte se integrativa como prova de dominio de conhecimentos e de habili dades mentais, segundo os objetivos visados no processo educativo.

A ênfase do processo avaliativo passarā a residir:

- Por parte do professor, na precisão da "codificação" das informações, desde a organização dos componentes curriculares até a elaboração de problemas, questões, textos ou instrumentos de testa gem do aproveitamento discente.

- Por parte do aluno, na "decodificação" das informações recebidas em seus desempenhos destinados à avaliação do rendimento. Na apuração dos resultados da avaliação, caberá ao profes sor, não mais como emissor mas como receptor, interpretar (redeco dificar) as respostas do aluno e, atravēs delas, obter as informa ções necessārias para um redirecionamento da atuação docente e/ou para uma adequada recuperação do aluno nos pontos fracos evidencia dos em sua aprendizagem.

A capacidade de sintese, que representa a culminância da aprendizagem, será comprovada num desempenho final atravēs de ins trumentos avaliativos elaborados conforme o tipo de currículo adota do.

Em termos operacionais, na organização destes instrumen tos deverá ser estabelecido o nível mínimo de aceitação, conforme critērios coerentes quanto ao conhecimento e habilidades considera das indispensāveis para que o estudante atinja o grau de sifuciēn cia convencionado.

As avaliações realizadas no decorrer das atividades plane jadas serão meramente indicativas do nỉvel alcançado pelo aluno na escala de valores adotados. Os desempenhos que não atingirem ou ul trapassarem o grau de aceitação estabelecidos servirão para fins me 
ramente classificatōrios.

A avaliação não serā, portanto, resultado de mēdias, uma vez que a aprendizagem por processo integrativo é irreversīvel.

0 tipo de avaliação proposto está baseado numa concepção dinâmica do processo ensino-aprendizagem, enquanto que a avaliação atravēs de médias corresponde a uma visão estātica, como se as estru turas mentais do indivíduo em determinado momento, sofressem um pro cesso de cristalização.

Como indicadores principais da àvaliação da eficiēncia do processo devem ser considerados:

- grau de variação da eficiēncia do produto a nỉvel indi vidua 1;

- tempo dispendido para alcançar os objetivos propostos;

- harmonia do rendimento nos diversos componentes curricu lares da mesma área e entre diversas āreas.

Em coerência com os pontos de vista apresentados poderse-ia interpretar a avaliação como sistema de comunicação, isto é, a avaliação como intercâmbio de informações na relação professor-alu no; o aluno, durante o período letivo, sem a preocupação de ser "jul gado", empenhar-se-à com autenticidade em bem "informar" ao profes sor sobre os aspectos de sua aprendizagem a corrigir ou a complemen tar.

\section{CONSIDERAÇOES FINAIS}

Com o presente estudo ē proposta uma sistematização de "en sino integrado" por organização e reorganização de estruturas men tais cada vez mais complexas, sistematização esta que atende à ie gislação vigente para nīvel de 10 grau.

A proposta tem como suporte teōrico a concepção piagetia na de desenvolvimento mental por estruturas e a concepção gestaltis ta de aprendizagem pela percepção.

Dada a complexidade decorrente de fatores que atuam no pro cesso ensino-aprendizagem, torna-se extremamente difficil apontar so luções ūnicas para o problema do ensino.

0 modelo proposto destina-se ao ensino de 10 grau, embora possa ser adaptado a qualquer nĩvel de ensino, admitindo-se, tambēm, sua adoção tanto em cursos completos como em apenas uma ou mais dis ciplinas ou unidades do programa curricular.

\section{AGRADECIMENTO}

A Professora Ely Campos da UFRGS, pela colaboração presta da durante a realização do trabalho.

BIBLIOGRAF IA CITADA

1. BORDENAVE, J.D.; PEREIRA, A. Estratégia de ensino-aprendizagem. 
Petrópolis, Vozes, 1977. 312p.

2. BRASIL. MEC. Lei 5692/71. Diärio oficial 12/08/71 e 18/08/71.

3. CHIAROTTINo, Z.R. Piaget: modelo e estrutura. Rio de Janeiro, Jo sé 01ympio, 1972. 94p.

4. FREDERICK, A.D. O ensinó integrado de cièncias. Revista do Cen tro de Educação-UFSM. Santa Maria, 1(1)35:45, 1979.

5. GEEMPA/INEP. Integração do ensino no curriculo por atividades e por área de estudos. Relatörio final. Porto Alegre, 1977.

6. MOORE, T.W. Educational theory an introduction. London. Roulledge Kigan Paul, 1974.

7. PIAGET, J. Lógica y psicologia. Barcelona. A. Redondo, 1969. 173p.

8. PIAGET, J. El nacimiento de la inteligência en el niño. Madrid, Aguilar, 1969. 314p.

9. PIAGET, J. Seis estudos de psicologia. Rio de Janeiro, Forense, 1969. 146p.

10. PIAGET, J. A epistemologia genética. Petrōpolis, Vozes, 1971. 110p.

11. PIAGET, J. e GARCIA, R. Las explicaciones causales. Barcelona, Barral, 1973. 233p.

12. PIAGET, J. Psicologia y epistemologia. Barcelona, Ariel, 1973, $189 \mathrm{p}$.

13. PIAGET, J.; INHELDER, B. Gênese das estruturas lógicas elementa res. 2a ed. Rio de Janeiro, Zahar/MEC, 1975. 356p.

14. ZILLES, U. Interdisciplinaridade no ensino e na pesquisa. Revís ta do Centro de Ciências Sociais e Humanas-UFSM. Santa Maria $4(2): 219-229,1979$.

Recebido em dezembro, 1983; aceito em dezembro, 1983. 